\title{
Regulation, Media Literacy and Media Civics
}

\section{Roger Silverstone}

The London School of Economics and Political Science

To be published (in German) in:

Axel Zerdick, Arnold Picot, Roger Silverstone, Jean-Claude Burgelmann, (eds.) (2002, in press), E-merging Media: the digitalisation of media economics, European Communication Council Report, Berlin; Springer.

(an earlier and much shorter of this paper appears in:

Amy Mahan, Robin Mansell and Rohan Samarajiva (eds.) (2002) Networking Knowledge for Information Societies: Institutions \& Interventions, Delft: Delft University Press) 
The locus of our regulatory concerns need to shift. In the new media world, a world that still includes old media, and old but yet resistant values driving institutional processes of mediation, the concern with markets, competition, and content needs to be rethought. This is not only because of the decline of spectrum scarcity, or the incapacity of national governments to control international flows of information and communication, but because new media are challenging what it means to be human, through their increasing salience as both information and communication resources, and as such as crucial components of our relational infrastructure and our social life.

I want to suggest, in this short essay, that an understanding of what it is to be human is, or certainly should be, the central question underlying, and in the final analysis regulating, the development of the mediated world in which more and more of us live, and by which almost all of us are affected. I intend to argue that existing forms of media regulation, at best operationalisations of what can be called applied ethics (Christians, 2000), at worst mindless enforcements of vested political or commercial interests, are not sufficient as guarantors of humanity or culture. Regulatory reform is still mostly a matter for governments and media industries and a matter of establishing professional and commercial guidelines for practice (variously enforced) without conscious attention to first principles of social action or media representation, and without addressing other ways of enabling not just a responsible and an accountable media, but a responsible and accountable media culture. A responsible and accountable media can be encouraged and regulated, however imperfectly and however vulnerably. A responsible and accountable media culture is another matter entirely, for it depends on a critical and literate citizenry, and a citizenry, above all, which is critical with respect to, and literate in the ways of, mass mediation and media representation. 
And I wish to suggest that at the core of such media literacy should be a moral agenda, always debated, never fixed, but permanently inscribed in public discourse and private practice, a moral discourse which recognises our responsibility for the other person in a world of great conflict, tragedy, intolerance and indifference, and critically engages with our media's incapacity (as well as its occasional capacity) to engage with the reality of that difference, responsibly and humanely. For it is in our understanding of the world, and our willingness and capability to act in it, that our humanity or inhumanity is defined.

\section{Media as environment}

As Cees Hamelink (2000) has recently pointed out, the media are central in this increasingly urgent project of identifying what constitutes our humanity precisely because they are at the forefront in representing, through endless sequences of narratives and images, the "historical reality of dehumanisation on a grand scale" $(2000,400)$.

And the media are indeed quite central to our capacity to be and to act in the world, as Marshall McLuhan (1964) once upon a time noted. It was he who most forcefully suggested that media, all media, are extensions of ourselves. They create and sustain an encompassing cultural environment which we all share. As we enter a digital age, one in which both the speed and range of communication seems to be have been so intensified; as we shift from, at best, an active engagement with our singular media to an increasingly interactive engagement with our converging media, media which give us the world, access to the world and information about the world, we are confronted with this McLuhanistic vision even more insistently.

Of course McLuhan profoundly misrepresented the totality and homogeneity of media as providing a kind of cultural blanket over all peoples of the world. He persistently disregarded the significance of geography and society as in turn mediating power and access to material and symbolic resources. 
Nevertheless, and despite its political innocence, this mediated cultural environment is as significant, it might be said, for the human condition as the natural environment is. Though it is rarely so remarked upon. Indeed both have holes in their ozone layers, chemical and moral in turn. Both are subject to the depredations and exploitations of the insensitive, the malicious and the self-interested. So although this environmental perspective makes, perhaps, more sense now than it ever did, it leaves untouched the thorny questions of who and what we are, and of how what we are in turn affects the ways in which media emerge and develop. And its still fails to register mediation as both a social and a political process. In other words, the humanity and inhumanity at the heart of the dynamics of mediation are left unexamined; they are presumed to be unproblematic.

Similarly, regulatory discourse rarely examines why regulation should take place, in the first place. Its presumptions about public interest, freedom of expression, rights to privacy, competition policy, intellectual property and the like presume an ordered or at least an orderable world, and indeed a world that would benefit from deliberative, and presumably accountable, regulation. Yet at best regulatory procedures, focusing on producers but addressing consumers, are based on an acknowledgement and an acceptance of what I have already called applied ethics: sets of morally informed but rarely interrogated prescriptions for, or proscriptions of, practice. The main beneficiary of such regulatory impulses and practices is the putative citizen, in his or her public and private life. In such present regulatory discourse and practice such citizens need to be protected against the depredations of untrammelled vested interests, be they commercial or imperial. They need to be given freedoms to speak and to be heard; they need to be given freedoms of choice. They need to be consulted on how regulatory policies are formed and implemented (Collins and Murroni, 1996).

But who is the citizen these days? And how has his or her status as citizen been affected by the media, both old and new, both broadcast and interactive? In what ways do our media enable or disable our capacity to relate to each other as citizens, but also as human beings? In what ways do 
they enable or disable us as ethical beings in our relationship to the world? In what ways do the media both address us as, and enable us to be, global citizens, participants and actors in natural, commercial and cultural environments all of which extend beyond both the immediacy of neighbourhood and nation?

\section{Home ...}

In an earlier essay (Silverstone, 1999) I argued that almost all our regulatory impulses, those that engage with the ownership of media industries on the one hand and those that concern the welfare of the family on the other, are between them concerned with the protection of home. What links them is a preoccupation with content: with the images, sounds, narratives and meanings which are transmitted and communicated daily, and over which regulators increasingly feel they have little control. What appears on the page or on the screen, what is represented, especially in its consistency or inconsistency, its decency or indecency, its intrusiveness, is deemed to be important precisely because it has been allowed to cross this principal threshold, seeping into private spaces and private lives. This was, of course, the impetus for the earliest attempts at content regulation, in the Hays Code, for the cinema. But these anxieties and the regulatory attempts to manage them have become more insistent as twentieth century media migrated away from public to private screens, and from shared sitting rooms to solitary bedrooms.

Banal though it may seem, the media are seen to be important because of the power they are presumed to exercise over us, at home, a power that no amount of audience research can quite completely deny, and of course which most of us believe, one way or the other, naturally to be the case. Home, of course, needs to be understood in both literal and metaphorical senses. The defence of home is a defence of both the private spaces of intimate social relations and domestic security - the household; as well as of the larger symbolic spaces of neighbourhood and nation - the collective and the 
community. The two are complex in their interrelationship and do not always share common interests. Yet both are threatened by the media extension of cultural boundaries: both laterally, as it were, through the globalisation of symbolic space, and vertically through the extension of accessible culture into the forbidden or the threatening. In both cases home has to be defended against material breaches of symbolic security.

The liberalisation of mainstream media and telecommunications in the 1980's and 1990's by a neo-liberal Conservative government brought with it an unexpected and unwelcome reduction in the capacity to control the flow of media content into the UK. Self induced de-regulation in one context and for one set of dominating economic reasons produced, as it was bound to, a moral panic in another context, that of culture. The Broadcasting Standards Council was, as a consequence, created to protect both the vulnerable child at home and the vulnerable home-land as if it were a child. Current debates on the future of public service broadcasting in the UK rehearse the same dilemmas, for once again what is at stake is the moral integrity both of the home and the nation, in its citizen's capacity to exercise, both privately and publicly, meaningful choices (a precondition for a moral life) as well as a perceived need to protect that same citizen from the immorality of meaningless or threatening choices that unregulated commerce might be expected to bring in its train.

For every de-regulation there is a re-regulation, but not always in the same domain, and rarely for clearly defined or well-examined reasons.

Competition policy is, therefore, as much about, and has consequences for, such breaches of personal security and domestic integrity - of the rights of the person and the personal - as it is about cross-media ownership and the future of public service broadcasting and the public sphere. Indeed it is precisely the private which is at stake in the discussions and deliberations on the latter.

And yet while regulators struggle to control and direct, to label and to licence content (as well as competition), parents and families struggle over a personal 
and private culture, shaping and protecting the domestic spaces where public and private moralities are supposed to coincide. This is a struggle for control, a struggle which propagandists, advertisers, television schedulers and portal designers well understand. And it is a struggle which parents understand too, as they argue with their children over time spent on-line. It is a struggle which at least in part defines, across lines of age and gender, the particular politics of individual households.

Regulation is, then, a private as well as a public matter. It takes place in frontrooms as well as in debating chambers, in the cut and thrust of discussions over viewing habits, as well as in international debates over v-chips and transborder media flows. In both these environments what is being fought over are the rights of, and control over, representation: of the availability of, and access to, the continuities and consistencies of both the immediacy, and the flow, of images and narratives. And in those representations what is at stake are the rights to define a relationship: between what is known and not known, between what is valued and not valued, between what one believes to be the truth and what one suspects as falsehood, and between what one lays claim to and what one can discard in one's relationship to the rest of the world. What is at stake, in these moments and mechanisms of regulation is, essentially, a moral order.

\section{... And away}

As we become increasingly dependent on the mediated word and image for our understanding of what takes place beyond our front door; as everyday life, in its taken-for-granted ordinariness, becomes inseparable from the mediations that guide us through it, and connect or disconnect us from the everyday lives of others; how the media position us, or enable us to position ourselves, becomes crucial.

As citizens we are expected to take responsibility for, and to act responsibly in relation to, ourselves, our neighbours and also the strangers amongst us. 
Such expectations have been, arguably, undermined by (among other things) a century of electronic mediation, which has led to increasing privatisation and individualisation. The dominant trope in the analysis of twentieth century public life has been its erosion: the palpable lack of care, the paradoxical lack of communication, has been revealed in increasing alienation from the formal processes of politics and engagement in public life; perhaps not for all, but for many, especially in the wealthy and highly mediated democracies of industrial society.

These societies, equally it goes without saying, are becoming increasingly connected to each other. What imperialism once enforced, globalisation now enables, or indeed requires: a mutuality of increasingly highly stratified economic and financial structures and processes; a shared but still massively and unevenly discomforting physical environment; a political space that no longer knows, nor much cares about, national boundaries and territorial sovereignty; networks of information and communication that shrink social and cultural space and time to the size of a handset.

In this context, and taking the broadest sweep, problems of regulation become problems of governance, in which order and accountability are dreamed about on a global scale, and at the level of states and trans-national non-governmental organisations. Foreign and domestic policy converges. Somehow even these dreams depend on a notion of citizenship, though a transcendent one, but they still require an engagement with the human - and they challenge it too. However they leave untouched and unexamined, for the most part, the individual in his or her humanity, in his or her sensibility. In what ways, if at all, can or should this humanity be affected by our regulatory impulses and institutions? In what ways should this humanity (or its lack) inform and affect our attempts at regulation and governance?

Early commentators, both utopian and dystopian, on the emerging late nineteenth century wireless and telegraphic space recognised the implications of what has subsequently come to be known as the double life of media and communication: that they separate as well as connect. This paradox 
inevitably calls the lie to any contemporary notion of the media's role in what is called the death of distance. It raises the question of isolation and not just privatisation - and isolation of both the individual and of the group. It also raises the question of the illusion of connection: that in our mediated innocence, in our mediated naïveté, that we are unable to recognise how imprisoned we are, how easily blinded we are, by the mediations that apparently link us together. And it is somewhat ironic to observe that the supposed revolution in media culture occasioned by the arrival of digital and on-line technologies should be seen to be so singular and radical, above all in their capacity to transcend the limits of electronic communication, limits perfectly well recognised (and feared) throughout the analogue twentieth century (de Sola Pool, 1977; Marvin, 1988).

As I have argued elsewhere (Silverstone, in press) there is often quite a fundamental confusion in much of the writing on the sociology and geography of new media. Time-space distanciation, or time-space compression, even ideas of the network society, suggest a profound and misleading elision between two kinds of distance: the spatial and the social. It is presumed in these discussions that the electronic mediation of physical or material connection provides at the same time, social, cultural or psychological connection. The technologically enabled transformation of time and space which marked the entry into the modern world certainly provided new conditions and possibilities for communication, communication that provided connection despite physical separation. Yet the contradictions at the heart of such communication become even more profound the more we insist that electronic mediation brings no penalty when it comes to understanding and caring for the other. Indeed when we insist, on the contrary, that our world view is now global in its reach. That there is no escape. That nothing can be hidden, nothing can be, or is, ignored. But of course it can.

My point is that distance is not just a material, a geographical or even a social category, but it is, by virtue of all of these and as a product of their interrelation, a moral category. The overcoming of distance requires more than technology and indeed more than the creation of a public sphere. It 
requires what I have called proper distance (Silverstone, in press). Proper distance is the critical notion that implies and involves a search for enough knowledge and understanding of the other person or the other culture to enable responsibility and care, as well as to enable the kind of action that, informed by that understanding, is in turn enabling. We need to be close but not too close, distant, but not too distant.

\section{Proper Distance}

The media have always fulfilled the function of creating some sense of proper distance, or at least they have tried, or claimed to be able, to do so. In the reporting of world events, the production of news, the fictional representation of the past, the critical interrogation of the private lives of public figures, the exploration of the ordinariness of everyday life, what is involved, in one way or another, is a negotiation between the familiar and the strange, as the media try, though always imperfectly, to resolve the essential ambiguities and ambivalences of contemporary life.

Yet such mediations have tended to produce, in practice, a kind of polarisation in the determinations of such distance. The unfamiliar is either pushed to a point beyond strangeness, beyond humanity; or it is drawn so close as to become indistinguishable from ourselves. And, it should be said, there is also very little sense that we are the objects of the others' gaze, that how we are seen and understood by those far removed from us also matters; we need to see and understand that too. Perhaps this has never been more the case than now.

On the one hand we find ourselves being positioned by media representation as so removed from the lives and worlds of other people that they seem beyond the pale, beyond reach of care or compassion, and certainly beyond reach of any meaningful or productive action. Technology has a habit of creating such distance, and the bureaucracies that have been built around technologies have in the past, and with cataclysmic effects, reinforced this 
sense of separation and alienation, this immorality of distance (Bauman, 1993). This is certainly and obviously the case in times of conflict, but it is rarely far away even in peace.

Per contra, the representation, just as frequent and just as familiar, of the other as being just like us, as recoupable without disturbance into our own world and values has, though perhaps more benignly, the same consequence. We refuse to recognise not only that others are not like us, but that they can be made to be like us. What they have we share. What they are we know. They are as they appear in our documentaries and in our advertisements. Such cultural neo-imperialism represents the other side of the immorality of distance, in its refusal to accept difference, in its resistance to recognising and to valuing the stranger. Perhaps this could be called the immorality of identity.

In both cases we lose a sense of both the commonality and difference that should inform the ethics of how we live in the world. Either way we lose the capacity effectively to grasp both what we share and what we do not share as human beings. The irony of the electronically mediated century just passed, in which we have come to believe that the immediate and the visible is both necessary and sufficient to guarantee connection, is that this apparent closeness is only screen-deep.

Distance can, therefore, be proper (correct, distinctive and ethically appropriate) or it can be improper. If improper distance can be, and is, created, inter alia, through the mediations that electronic technologies provide for us, then it follows that we can use the notion of proper distance as a tool to measure and to repair the failures in our communication with and about other people and other cultures and in our reporting of the world, in such a way as our capacity to act in it is enabled and preserved (Boltanski, 1999; Silverstone, in press). And it follows too that we can use the notion of proper distance as a way of interrogating those arguments, most recently in the analysis of the supposed miraculous capacity of the Internet, that mistake 
connection for closeness, and closeness for commitment, and which confuse reciprocity for responsibility.

It is with the convergence between the public and the private, the personal and the social, that the notion of proper distance seeks to engage. And it is at this interface, perhaps increasingly confused and confusing, that social beings, citizens real or manqué, need both to confront a moral agenda that is appropriate to the conditions both of the mediation of the world, and appropriate to the resulting mediated world, the world in which the other person appears to us - as through a glass darkly.

\section{Media Literacy and Media Civics}

Regulation has always been a technical activity. To suggest that it should also be a moral one has its dangers. Yet these dangers need to be confronted. What is missing so often in the regulatory discourse is the question: regulation for what, and for whom?

The focus on content, on media as representational technologies, is in many ways atavistic. It brings back concerns that many had thought long since buried in the analysis of mediation: concerns with ideology, effects, false consciousness, even. On the other hand our regulatory concern is still implicitly (and sometime explicitly) based on such assumptions as these: a political economy in which ownership determines content, and where content in turn determines meanings and effects.

Yet even if we can acknowledge, with recent media theory, that this linearity is misconceived and that receivers of communication, wherever they happen to be, and understood as audiences or users, are active interpreters and mediators of even the most consistent and dominant of media representations, it is still possible, reasonable and necessary to acknowledge the persistent power of our media's mediations. Media are nothing if they do not convey meanings, and even if we can (and we can) negotiate those 
meanings for ourselves, and distance ourselves from those meanings we find unacceptable or unpalatable, in the absence of others - both other meanings and other realities - our perceptions of the world can not but be increasingly and consistently framed by what is seen and heard through screens and audio-speakers.

The multiple negatives of the last paragraph are intended, and intended to be, instructive. There is inevitably and necessarily a need for caution in any kind of moral position lest it be seen as, or become, moralistic. So it needs to be understood that the present argument is not for a new kind (or even an old kind) of censorship. On the contrary at issue are the presumptions and preconditions for our understandable (perhaps even natural, at least sociologically speaking) concern for regulation. Perhaps it is time to recognise that regulation should not just be concerned with the protection of our own securities and of those we hold dear or for whom we have some formal, familial or even national, responsibility.

Regulation should address the wider and, I have suggested, the much deeper issue of our relationships to others, to those for whom we have no formal responsibility, to those who are distant in space or culture, the strangers amongst us, our neighbours abroad; but for whom our basic humanity requires that we should care. This is of course a tall order. However it suggests a shift, and one that it might well be argued is long overdue. It involves a shift away from regulation as narrowly conceived in the minds and practices of parliaments and councils, towards a more ethically oriented education, and towards a critical social and cultural practice which recognises the particular characteristics of our mediated world. We once upon a time taught something called civics. It is perhaps time to think through what civics might be in our present intensely mediated century.

In one sense, perhaps, we could say that we have been here before, at least in part. The mid and late nineteenth century saw, certainly in the UK but also in Western Europe and in the US, the rise of a political project, broadly speaking, to incorporate disparate and displaced populations into civic culture. 
The displacement was for the most part, internal: populations leaving the land and traditional cultures and finding themselves in cities and within urban and popular cultures. Industrialisation was having profound social consequences, and the social consequences involved very significant and destabilising shifts in the communicative infrastructures of everyday life. Such destabilisation and the consequent danger of anomie amongst an increasingly concentrated population was clearly a source of anxiety amongst elites - both legitimate and paranoid. Nation states were being consolidated and any source of political resistance was clearly a focus of concern. At the same time democracies were maturing and working class movements were themselves encouraging the displaced and disadvantaged - the still excluded - to generate the necessary social and cultural capital to participate increasingly fully and meaningfully in the public affairs of the strengthening state. There were both campaigns for, and political commitments to enable, mass literacy. Workers educational movements engaged the mature; increasingly universal primary and secondary education engaged the maturing.

All participation is double edged. It is both enabling and constraining. The literacy of the book, the newspaper and the pamphlet brought with it both the means for incorporation into national culture and the means for the suppression of any alternative, but it also brought an increasingly informed, reflective and cultured citizenry. Vernacular literacy was a precondition of such participation and reflection. To pretend that this was not a regulatory project would be naïve. At the same time, however, it was also a liberating one - and in essence and in intent, very often, a genuinely moral one, whatever we might think about Victorian ethics. The focus of that first regulatory impulse was clearly that of the nation state, a state enabled initially by the Gutenberg revolution (Eisenstein, 1979) and secured - at least for large slices of the twentieth century - by Marconi's and Baird's (Scannell, 1989). The focus, now, arguably, is post-national, if by that can be meant the redrawing and puncturing of the boundaries around and between states in the face of globalising culture. 
Whereas the nineteenth century civic project required the literacy of the written text, a literacy that was both literal and critical, the twenty-first century civic project requires a literacy of mass mediated, electronic texts - and this too needs to be both literal and critical. But there the similarity ends. For the twenty-first century brings with it a different cultural and political challenge, in which the different media, both analogue and digital, are differently implicated in the structures and dynamics of everyday life.

For most, the literacy of the book was a literacy of decipherment: to be able to read, to follow, to understand, to appreciate. It required considerable application and the acquisition of sophisticated skills. Media literacy in an age of broadcasting was much less demanding, and the ease of access to complex audio-visual texts was seductive. The mass media were seen as more powerful not just because they were mass, because they dimmed critical skills, the skills of engagement and struggle with complexity (Rosenberg and White, 1957). It was not thought that literacy, at least in the terms where it was appropriately applied to the written text, was necessary. Indeed the mass media were seen to be destroying and undermining that kind of literacy. It is possible, of course, to argue that the Internet has created its own demands for a new kind of literacy, text based but requiring new skills of organisation and decipherment, and that this is already transforming the structured illiteracy of the age of broadcasting. I would suggest that for the most part the literacy required for the Internet is still seen to be essentially technical, and is rarely approached as requiring more sophisticated skills.

In both the new and the old media, therefore very little attention has been given to media literacy as a critical activity. Very little attention has been given to media literacy as a civic activity. Very little critical attention has been given either to literacy or civics as an alternative to the blunderbuss of media regulation, or to the possibility of developing an ethical agenda which would inform such a project.

In a recent paper Rüdiger Funiok (2000) has addressed some of these questions through an interrogation of audience ethics, that is the responsibility 
that users of the media can, and should, develop for themselves. He cites Cees Hamelink's $(2000,400)$ conclusion that "Media consumption should be viewed, like professional media performance, as a social practice which implies moral choices and the assumption of accountability for these choices". This is a complex demand, of course, and extends way beyond the still limited framework that I am pursuing here. Yet the notion of responsibility is crucial, responsibility for oneself, and for others; in the context of the family, of course, but also in the context of neighbourhood and nation (imagined communities both) and, now, in the context of a global culture and a global imaginary, which the world's media are daily creating.

Media literacy in this context is a political project, just as media civics is a "literary" one. The former is a pre-requisite for full participation in late modern society, involving as it does the critical skills of analysis and appreciation of the social dynamics and social centrality of media as framing the cultures of the everyday. Media literacy above all requires an understanding of the nontransparency of media and of the moral implications of that non-transparency. And it requires an understanding of mediation as a social and political process. Media civics, correlatively, depends on media literacy. Media civics, crucial to citizenship in the twenty-first century, requires the development of a morality of responsibility and participation grounded in a critical engagement with mediation as a central component of the management both of state and global politics and that of everyday life: both of the system and the life-world.

There is very little surprise in these observations, at least from the point of view of the academic study of the media, but equally there is very little surprise in the observation that these fundamental critical principles have hitherto for the most part failed to inform both the deliberations of policy makers, and the judgements of citizens.

\section{Conclusion}

Our regulatory impulses need to be both informed and moderated by these concerns. Citizenship requires responsibility and to exercise such 
responsibility well and thoroughly in turn requires the need to be able to see the world and to see through our media's limited and inadequate representations of it.

I have proposed the notion of proper distance as a framing device for such a project. Media civics has to burst the bounds both of the nation state and the narcissistic limits of concern only with the individual and the self. Its regulatory embrace should bring the other into its ambit. A sense of proper distance is a moral sense, one in which the relationship between proximity and distance is mediated by an effective measure of understanding, care and responsibility. We need to know about each other in a way that can only involve a constant critical engagement with our media's representation of the other. Such engagement is as important to our relationships to our neighbours as to the strangers both amongst us and far away. The everyday, hitherto the site of an unreflecting gaze, can, and should, be made more critically aware - for that is, after all, what our media can enable for us, if there is such a mind to do so. Representational ethics, the ethics informing the production and reception of the images and stories of both old and new media, emerges from these discussions as a new and compelling concern.

Regulation is, therefore, not just a matter of production. And here as in other dimensions of media dynamics, production and consumption blur; the boundaries between them become indistinct. Equally the full responsibility for a moral agenda informing media practices should lie not only with audiences and users. It is the interests and understandings of audiences and users, the urgent requirements of citizenship, which should continue to constrain and increasingly determine the regulatory process. We are of course, responsible for ourselves. But, as Emmanuel Levinas insists, if we are to claim a full and proper humanity we must claim responsibility for the other. In this sense, as well as reading, we might need to regulate, against the grain. 


\section{References}

Bauman, Zygmunt (1993) Postmodern Ethics, Cambridge: Polity Press

Boltanski, Luc (1999) Distant Suffering: Morality, Media, Politics, Cambridge: Cambridge University Press

Christians, Clifford (2000) 'An intellectual history of media ethics', in Bart Pattyn (ed.) Media Ethics: Opening Social Dialogue, Leuven: Peeters, 15-46

Collins, Richard and Murroni, Cristina (1996) New Media, New Policies, Cambridge: Polity Press

de Sola Pool, Ithiel (1977) The Social Impact of the Telephone, Cambridge: MIT Press

Eisenstein, Elizabeth (1979) The Printing Press in an Age of Social Change, 2 Vols, Cambridge: Cambridge University Press

Funiok, Rüdiger (2000) 'Fundamental questions of audience ethics', in Bart Pattyn (ed.) Media Ethics: Opening Social Dialogue, Leuven: Peeters, 403422

Hamelink, Cees (2000) 'Ethics for media users' in Bart Pattyn (ed.) Media Ethics: Opening Social Dialogue, Leuven: Peeters, 393-401

Marvin, Carolyn (1988) When Old Technologies Were New: Thinking About Communications in the Late Nineteenth Century, Oxford: Oxford University Press

McLuhan, Marshall (1964) Understanding Media, London : Routledge and Kegan Paul

Rosenberg, Bernard and White, David Manning (eds.) (1957) Mass Culture: The Popular Arts in America, New York: The Free Press

Scannell, Paddy (1989) 'Public service broadcasting and modern public life', Media, Culture and Society, 11(2), 135-166

Silverstone, Roger (1999) Why Study the Media?, London: Sage

Silverstone, Roger (in press) 'Proper distance: towards an ethics for cyberspace, in Gunnar Liestøl, Andrew Morrison, Terje Rasmussen (eds.) Innovations, Cambridge, Mass: MIT Press 